\title{
Endosialin and Associated Protein Expression in Soft Tissue Sarcomas: A Potential Target for Anti-Endosialin Therapeutic Strategies
}

\author{
Daniel J. O'Shannessy, ${ }^{1}$ Hongyue Dai, ${ }^{2,3}$ Melissa Mitchell, ${ }^{2}$ Shane Huntsman, \\ Stephen Brantley, ${ }^{2}$ David Fenstermacher, ${ }^{4}$ and Damon R. Reed ${ }^{5,6,7}$ \\ ${ }^{1}$ Translational Medicine and Diagnostics, Morphotek, Inc., Exton, PA 19341, USA \\ ${ }^{2}$ M2Gen, Tampa, FL 33612, USA \\ ${ }^{3}$ H. Lee Moffitt Cancer Center and Research Institute, Department of Biostatistics and Biostatistics, Tampa, FL 33612, USA \\ ${ }^{4}$ Department of Bioinformatics, Virginia Commonwealth University, Richmond, VA 23284, USA \\ ${ }^{5}$ Sarcoma Department, H. Lee Moffitt Cancer Center and Research Institute, Tampa, FL 33612, USA \\ ${ }^{6}$ Chemical Biology and Molecular Medicine Program, H. Lee Moffitt Cancer Center and Research Institute, Tampa, FL 33612, USA \\ ${ }^{7}$ Adolescent and Young Adult Program, H. Lee Moffitt Cancer Center and Research Institute, Tampa, FL 33612, USA
}

Correspondence should be addressed to Daniel J. O’Shannessy; doshannessy@morphotek.com

Received 9 November 2015; Accepted 30 December 2015

Academic Editor: C. Verhoef

Copyright (C) 2016 Daniel J. O’Shannessy et al. This is an open access article distributed under the Creative Commons Attribution License, which permits unrestricted use, distribution, and reproduction in any medium, provided the original work is properly cited.

\begin{abstract}
Endosialin (CD248, TEM-1) is expressed in pericytes, tumor vasculature, tumor fibroblasts, and some tumor cells, including sarcomas, with limited normal tissue expression, and appears to play a key role in tumor-stromal interactions, including angiogenesis. Monoclonal antibodies targeting endosialin have entered clinical trials, including soft tissue sarcomas. We evaluated a cohort of 94 soft tissue sarcoma samples to assess the correlation between gene expression and protein expression by immunohistochemistry for endosialin and PDGFR- $\beta$, a reported interacting protein, across available diagnoses. Correlations between the expression of endosialin and 13 other genes of interest were also examined. Within cohorts of soft tissue diagnoses assembled by tissue type (liposarcoma, leiomyosarcoma, undifferentiated sarcoma, and other), endosialin expression was significantly correlated with a better outcome. Endosialin expression was highest in liposarcomas and lowest in leiomyosarcomas. A robust correlation between protein and gene expression data for both endosialin and PDGFR- $\beta$ was observed. Endosialin expression positively correlated with PDGFR- $\beta$ and heparin sulphate proteoglycan 2 and negatively correlated with carbonic anhydrase IX. Endosialin likely interacts with a network of extracellular and hypoxia activated proteins in sarcomas and other tumor types. Since expression does vary across histologic groups, endosialin may represent a selective target in soft tissue sarcomas.
\end{abstract}

\section{Introduction}

Endosialin, also known as Tumor Endothelial Marker-1 (TEM-1) or CD248, was first described as a vascular endothelial cell surface antigen in human fetal fibroblasts [1]. These authors demonstrated monoclonal antibody FB5 reactivity in a significant proportion of tumor blood vessels, including those of sarcoma, while ostensibly being absent from normal tissues. Endosialin is classified as a C-type lectin-like protein and shares both sequence and structural homology with thrombomodulin (CD141) and complement receptor ClqRp (CD93) [2]. All three proteins are involved in, but not limited to, the process of angiogenesis.

Although the domain structure of endosialin is well characterized, the underlying biochemistry of this protein is not well understood. Studies have identified pericytes and reactive fibroblasts, two essential cell types required for tumor survival and growth, as the major sites of expression of endosialin. Pericytes and stromal fibroblasts derive from mesenchymal stem cells [3] and, as such, endosialin has been 
TABLE 1: Probe sets used in the present study.

\begin{tabular}{ll}
\hline Gene & Probe set(s) \\
\hline FN1 & merck-NM_054034_a_at \\
\hline COL1A1 & merck-NM_000088_at; merck-BC036531_a_at; merck2-DQ893571_at \\
\hline COL1A2 & $\begin{array}{l}\text { merck-BC042586_a_at; merck-CF125809_s_at; merck2-NM_000089_at; } \\
\text { merck2-AI983991_a_at; merck2-AK226074_a_at; merck2-BY794944_a_at }\end{array}$ \\
\hline COL4A1 & $\begin{array}{l}\text { merck-NM_001845_at; merck-AK058157_at; merck2-AL572880_at; } \\
\text { merck2-M10940_at }\end{array}$ \\
\hline COL4A2 & $\begin{array}{l}\text { merck-M24766_a_at; merck2-NM_001846_at; merck2-BM546367_a_at; } \\
\text { merck2-BQ014598_a_at }\end{array}$ \\
\hline COL4A4 & merck-M81379_a_at; merck-NM_000091_at \\
\hline COL4A5 & merck-NM_000092_at; merck-BC065843_at; merck2-D17391_at \\
\hline COL4A6 & merck-NM_033381_at; merck-AV659759_at; merck2-AL049291_at \\
\hline CAIX & $\begin{array}{l}\text { merck-ENST00000345014_at; merck-NM_001847_at; } \\
\text { merck-ENST00000358735_at; merck-AL049300_at }\end{array}$ \\
\hline EPAS1 & merck-NM_001216_at; merck2-DQ892208_at \\
\hline HSPG2 & $\begin{array}{l}\text { merck-NM_001430_at; merck-BC070392_at; merck-BC026731_at; } \\
\text { merck-AK023572_at }\end{array}$ \\
\hline
\end{tabular}

described as a mesenchymal marker. Pericytes are essential to the process of angiogenesis, especially neoangiogenesis, and serve as scaffolding for endothelial cells but also communicate with endothelial cells by direct physical contact and paracrine signaling pathways [4]. It is now accepted that the formation of solid tumors requires the proliferation of stromal cells to support cancer cell growth, invasion, and metastasis [5] and that the stromal cell compartment comprises a heterogeneous mix of cell types responsible for the formation of blood vessels as well as supporting a microenvironment commensurate with tumor growth and proliferation. The potential for pericytes to contribute to the formation of tissues in addition to vessels has also been described for osteoblasts, chondroblasts, fibroblasts, adipocytes [6,7], myogenic cells [8], and odontoblasts [9, 10]. The coordinated growth and cross-talk between stromal cell components are critical for establishing a microenvironment that can support the growth and maintenance of tumor cells. This is mediated, at least in part, through direct cell-cell interaction as well as through secreted molecules, including extracellular matrix components (ECM) [11, 12]. Taken together, these data suggest that endosialin plays a role in forming and/or stabilizing the tumor ECM and thus the tumor microenvironment, in addition to its roles in neovascularization and cross-talk between various cell types. Indeed, cell culture studies have demonstrated endosialin to be directly involved in regulating cellular proliferation [13] and in a subset of cells this proliferation appears to involve the PDGFR- $\beta$ pathway $[14,15]$.

It is now well established that endosialin expression in tumors is not restricted to tumor vessels but is also present in tumor stroma and in some instances expressed by tumor cells themselves. Studies in normal and neoplastic tissue have indicated expression of endosialin in tumor neovasculature within human colorectal cancer [16], breast cancer [17, 18], histiocytomas [19], highly invasive glioblastoma, anaplastic astrocytomas, metastatic carcinomas, and melanoma [20,21].

Based on the important role of stroma in supporting tumor growth and the activity of endosialin in supporting tumor stromal cell functions, clinical studies using a humanized monoclonal antibody, ontuxizumab (MORAb-004), are currently underway to determine the safety and clinical activity of blocking endosialin in patients with various cancer types [22]. Sarcomas are a diverse collection of cancers of mesenchymal origin which can affect all ages. Importantly, endosialin expression has been characterized directly on sarcoma tumor cells $[23,24]$. While overall incidence of sarcomas is $1 \%$ of all newly diagnosed cancers, it is relatively more common in younger ages consisting of $15 \%$ of childhood cancers and $8 \%$ of cancers in young adults. Metastatic sarcomas have a poor prognosis with few advances in recent decades $[25,26]$. Phase II studies have demonstrated few active agents even with a relatively low efficacy bar of $40 \%$ progression-free survival at 4 months [27]. A recently accrued but not yet reported phase II, randomized clinical trial (NCT01574716) investigated the addition of ontuxizumab to gemcitabine and docetaxel in adult sarcoma patients stratified by diagnosis into one of four groups of leiomyosarcoma, liposarcoma, undifferentiated, and other soft tissue sarcomas.

We therefore undertook a preclinical assessment into the relative expression of endosialin and PDGFR- $\beta$ in a novel, retrospective cohort of soft tissue sarcoma patients by immunohistochemistry (IHC) and gene expression. We further compared expression to other potential endosialinassociated proteins and with clinical characteristics including outcomes to address efficacy as well as enhance the development of these biomarkers in sarcoma and other patient populations. 


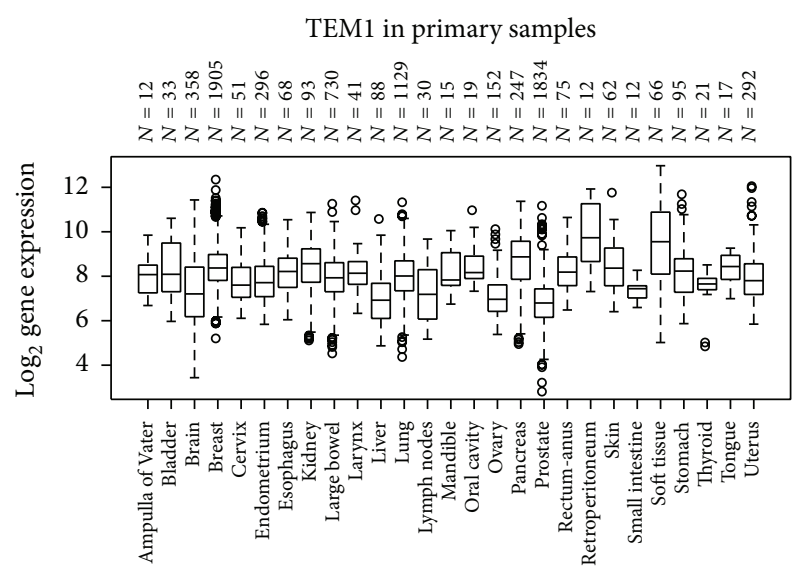

(a)

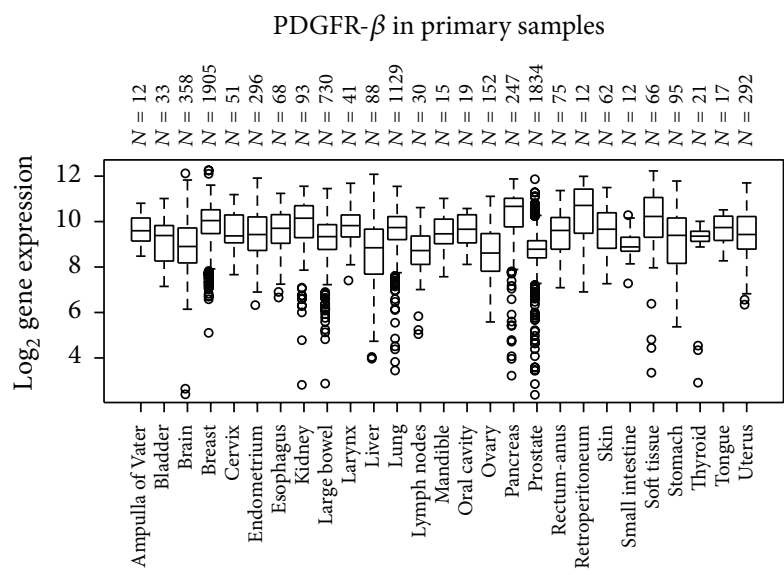

(c)
TEM1 in metastatic samples

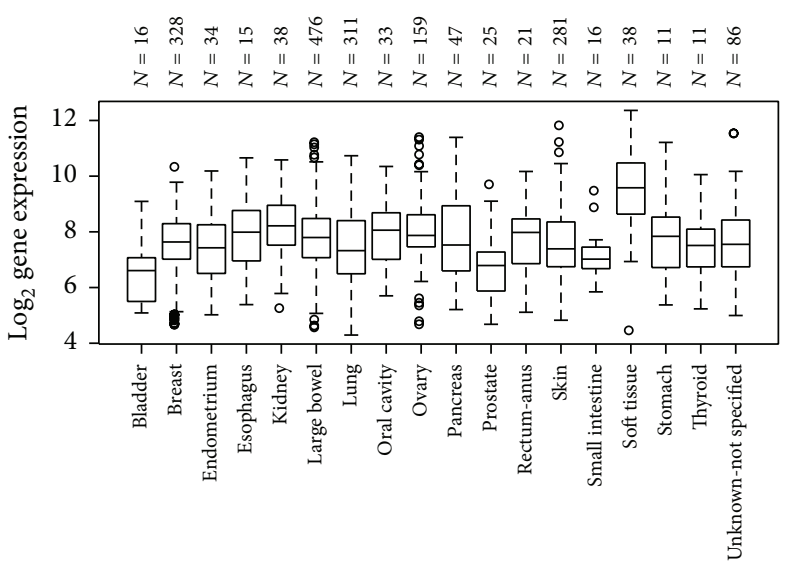

(b)

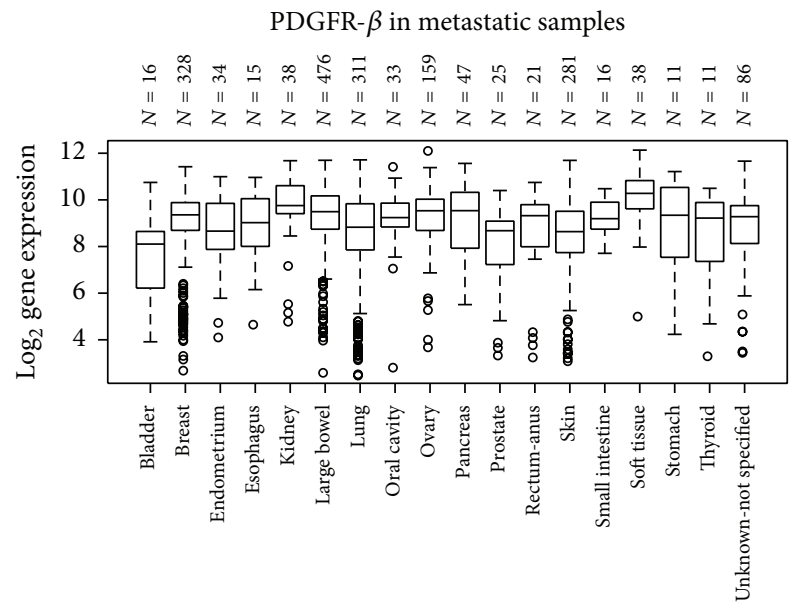

(d)

FIGURE 1: Expression of endosialin and PDGFR- $\beta$ across numerous solid tumors. Gene expression of endosialin and PDGFR- $\beta$ was evaluated across all tumor types in the Total Cancer Care ${ }^{\infty}$ (TCC) Data Warehouse in a total of 15,820 samples. The distribution of the expression level in each tumor type is represented by box plots, with the middle horizontal line representing the median and the box representing the 25 th to 75th percentiles. (a) Endosialin in primary tumors; (b) endosialin in metastatic tumors; (c) PDGFR- $\beta$ in primary tumors; and (d) PDGFR- $\beta$ in metastatic tumors. Both endosialin and PDGFR- $\beta$ are highly expressed in soft tissue tumors which are mostly comprised of sarcomas.

\section{Materials and Methods}

2.1. The Total Cancer Care Protocol. In 2006, Moffitt Cancer Center launched Total Cancer Care (TCC), an observational research study designed with the objective of following patients throughout their lifetime to identify and meet patients' needs [28], consenting to the TCC protocol that allows for lifetime follow-up, data sharing, use of tumor specimens for research and biomarker analyses, and the ability to recontact patients if there is a finding that could influence patient care, including clinical trials. The TCC protocol is a network of 17 hospitals, all of which adhere to the same procedures for collection and shipment of tissue for molecular analysis and abstraction of longitudinal clinical data. As of May 2015, over 123,000 patients have consented to the TCC protocol with more than 39,000 fresh frozen tumor specimens collected and molecular data on nearly half of the specimens. To ensure compliance with HIPAA and Human Subject Research requirements, an oversight committee monitors TCC operations and procedures.

2.2. Identification of Sarcoma Samples. Expression of endosialin and PDGFR- $\beta$ was calculated as described for all tumor samples that had a corresponding Affymetrix microarray. Sarcoma samples were identified and subtyped based on the pathology/histology data available in the Total Cancer Care Data Warehouse. Sarcoma tumor samples were ordered by $\log _{2}$ expression values for both endosialin and PDGFR- $\beta$ to determine quartile cutoffs for both genes. Within each quartile, twenty samples were selected in an effort to understand the levels of gene expression that correlated with positive IHC $H$-scores. This selection of samples in each quartile resulted in the identification of FFPE samples with $\log _{2}$ expression values ranging from 12.2 to 5.6 for PDGFR- $\beta$ and from 12.9 to 5.7 for endosialin. In total, 94 independent FFPE 


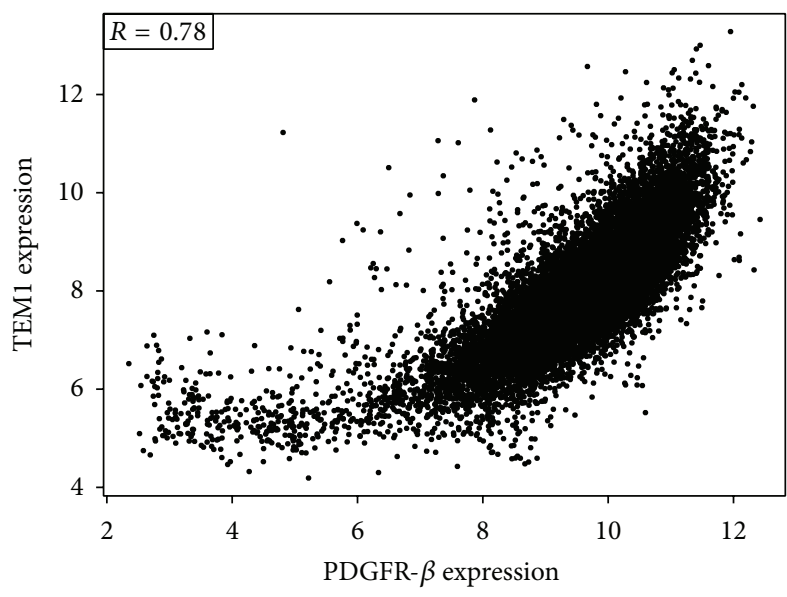

(a)

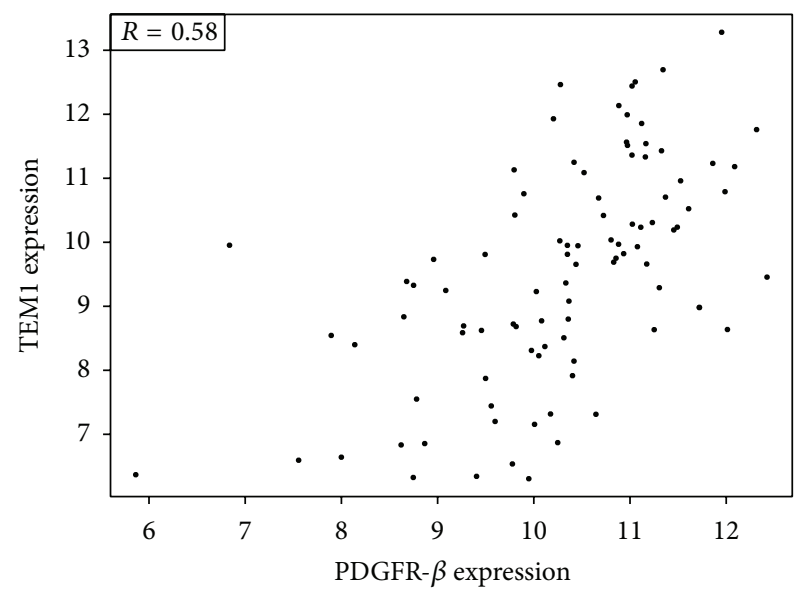

(b)

FIGURE 2: Correlation between endosialin and PDGFR- $\beta$ gene expression. Endosialin (TEM-1) and PDGFR- $\beta$ expression levels were assessed across all 15,820 samples in the TCC Data Warehouse (a) and in the subset of 94 sarcoma samples (b) and were shown to be highly correlated: $R=0.78$ and 0.58 , respectively.

samples were selected for IHC analysis for both endosialin and PDGFR- $\beta$.

2.3. Clinical Data. Samples were identified through Health Information Resources and consisted of deidentified samples. Clinical data including diagnosis and stage were abstracted electronically from the Data Warehouse. To confirm accurate information, deidentified pathology reports with all PHI redacted were reviewed. All samples were categorized as undifferentiated, leiomyosarcoma, liposarcoma, and other.

2.4. Immunohistochemistry-Endosialin and PDGFR- $\beta$. Immunohistochemistry (IHC) for endosialin was performed as previously described [29] using monoclonal antibody 9G5 on $5 \mu \mathrm{m}$ FFPE specimens. For the detection of PDGFR$\beta$, monoclonal antibody clone 28E1 (1:50 dilution; Cell Signaling) was incubated for $30 \mathrm{~min}$ as primary or Flex Rabbit Negative (Dako) as the negative control. Primary antibody was detected using Envision Flex HRP (Dako) for 30 min followed by Flex DAB+ Chromogen (Dako). All tissue sections were counterstained with hematoxylin for $2 \mathrm{~min}$. The H\&E and IHC stained slides were reviewed by a single ABP-certified pathologist using a protocol derived from standard methods for $H$-scoring [30-34]. The entire slide was scanned at 10x magnification, and the percentage of each degree of staining intensity in the tumor cells was determined: $H$-score $=(\% 0+)+(\% 1+)+(\% 2+)+(\% 3+)$. Each slide was examined twice at separate sessions to ensure that intraobserver variation was not a factor. Slides were evaluated without access to patient demographics or clinical information, and the original histopathologic diagnoses were not reviewed until the analysis was complete. No discrepancies with the original diagnoses were identified.

2.5. Gene Expression Data. Fresh frozen tumor samples from TCC consented subjects were collected and RNA
TABLE 2: Clinical characteristics of 94 sarcoma patients.

\begin{tabular}{lccc}
\hline Characteristic & & $N$ & $\%$ \\
\hline \multirow{4}{*}{ Age (years) } & Mean & 59 & \\
& SD & 16.5 & \\
& Range & $19-90$ & \\
\multirow{4}{*}{ Histotype } & Leiomyosarcoma & 28 & $29.8 \%$ \\
& Liposarcoma & 22 & $23.4 \%$ \\
& Undifferentiated & 34 & $36.2 \%$ \\
\multirow{2}{*}{ Stage } & Other & 10 & $10.6 \%$ \\
& I & 1 & $1.1 \%$ \\
\multirow{2}{*}{ Site of sample } & II & 9 & $9.6 \%$ \\
& III & 84 & $89.4 \%$ \\
\hline \multirow{2}{*}{ Vitals } & Primary & 55 & $58.5 \%$ \\
& Metastatic & 39 & $41.5 \%$ \\
\hline \multirow{2}{*}{} & Alive & 28 & $29.8 \%$ \\
& Dead & 66 & $70.2 \%$ \\
\hline
\end{tabular}

extracted. Sample amplification, labeling, and microarray processing were performed by the Rosetta Inpharmatics Gene Expression Laboratory (Seattle, WA). Samples were amplified and labeled using the NuGEN Ovation WB protocol and were hybridized to the Rosetta/Merck Custom Affymetrix microarray, the HuRSTA-2a520709 Affymetrix array (GEO GPL15048), following the standard Affymetrix protocol. Expression arrays were normalized using the IRON method (Iterative Rank-Order Normalization) [35]. The IRON array processing pipeline employs RMA background subtraction, Tukey's Biweight probeset summarization, and a novel pairwise (sample versus reference) IRON method that is able to largely handle violations of the symmetry assumption implicit in quantile normalization and traditional pairwise normalization algorithms. Endosialin and PDGFR- $\beta$ gene expressions were measured by probes merck-NM_020404_at 
TEM1 IHC

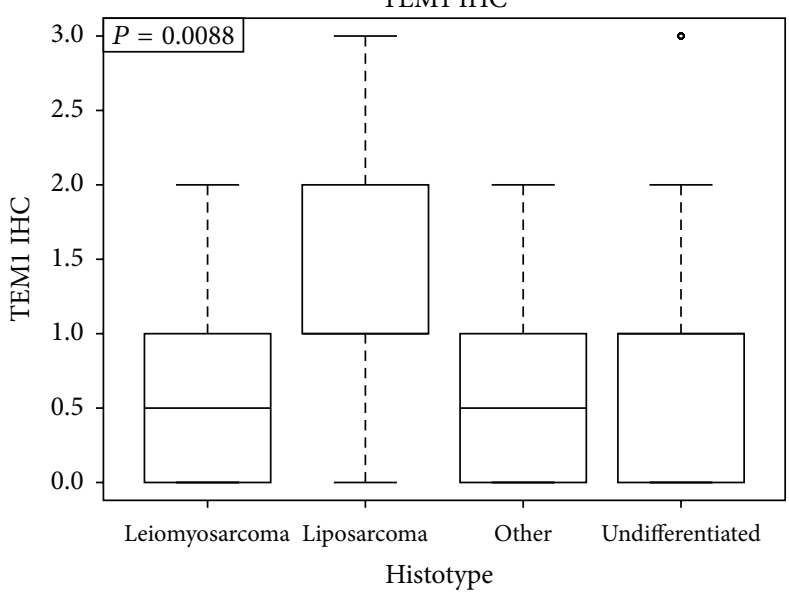

(a)

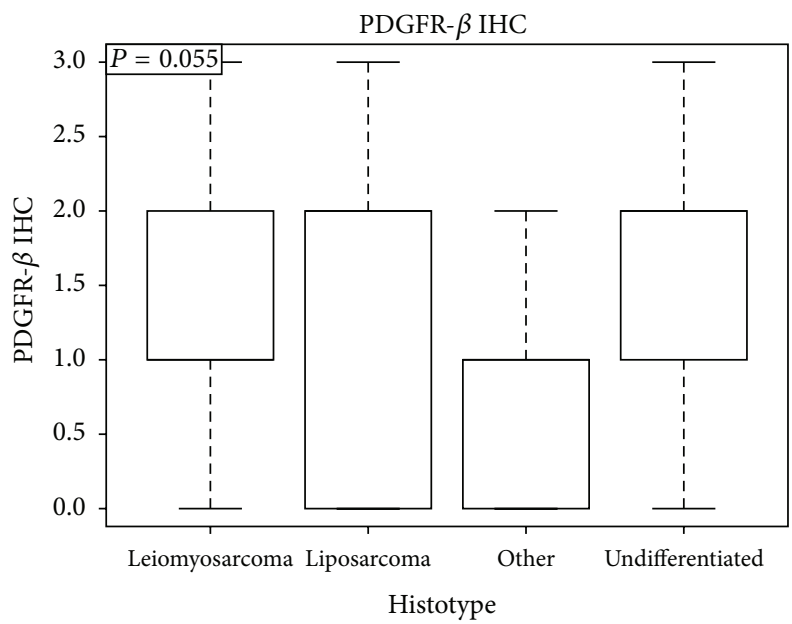

(c)

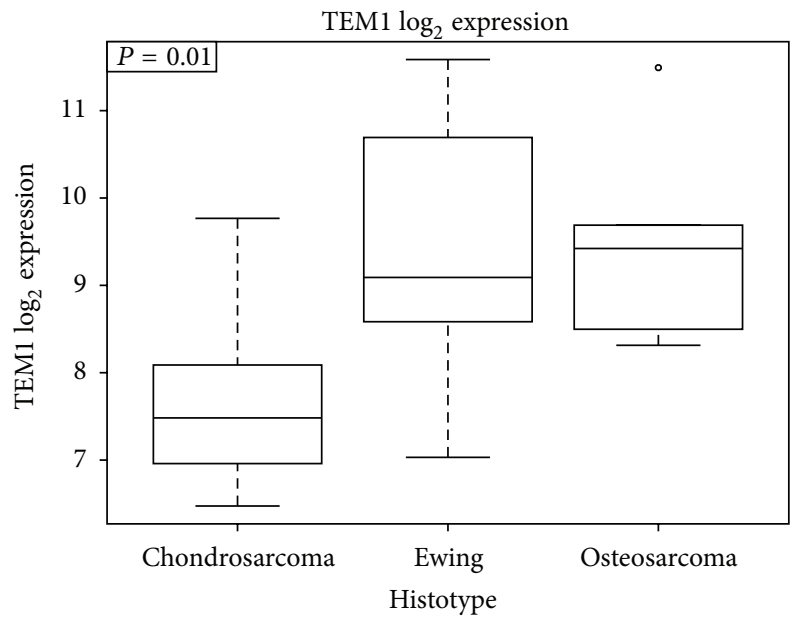

(e)

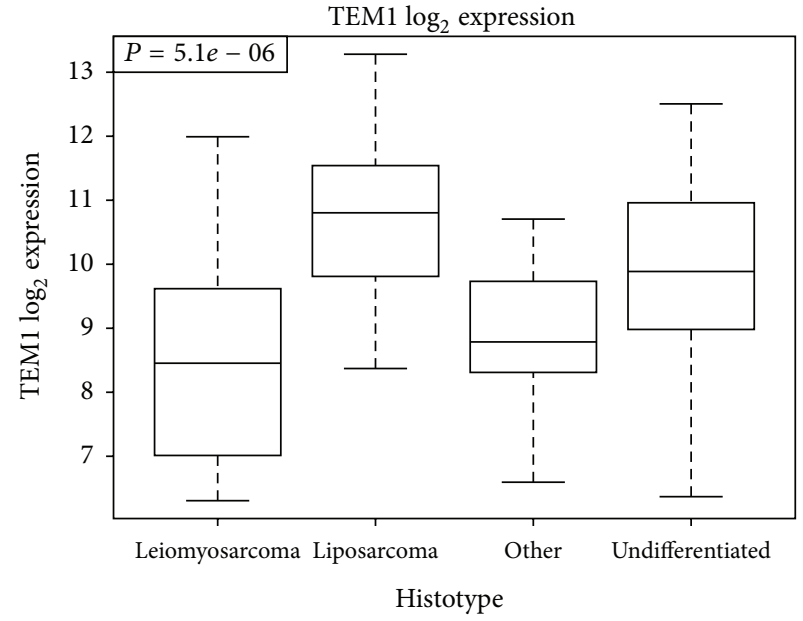

(b)

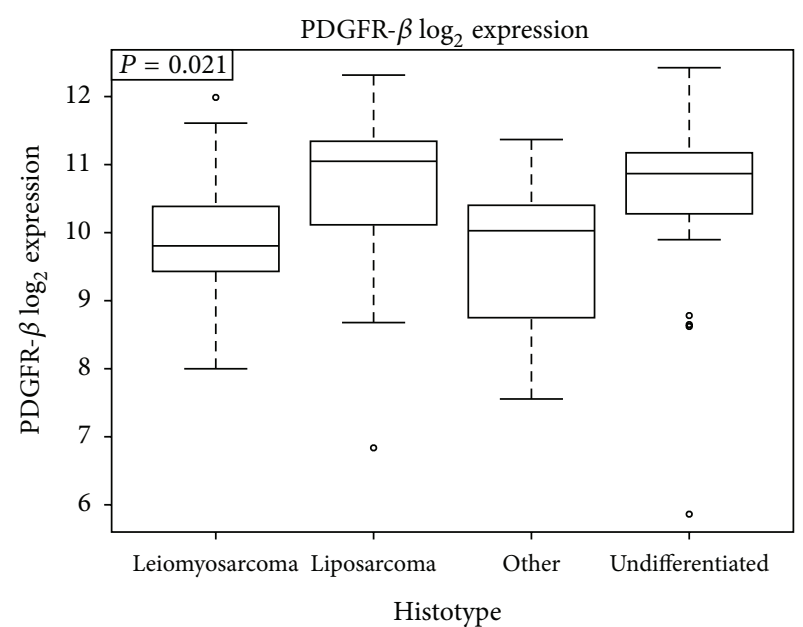

(d)

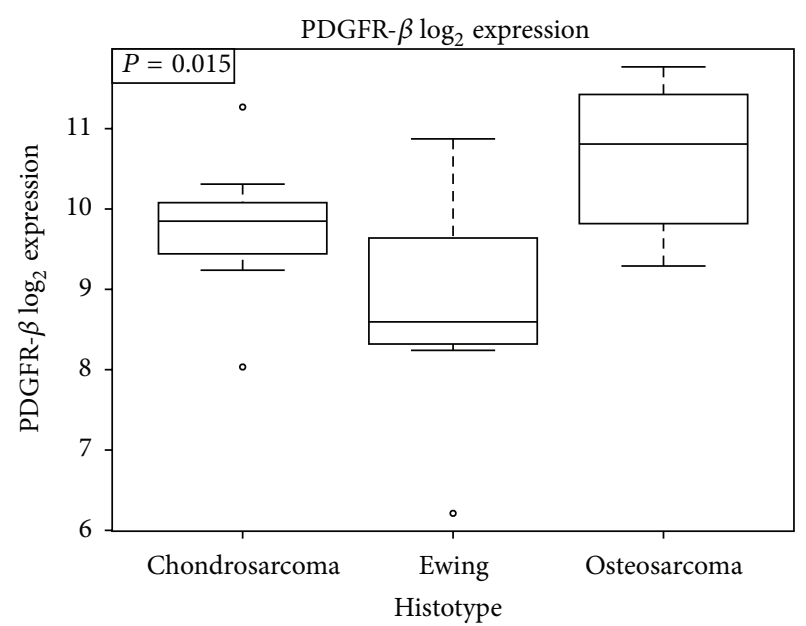

(f)

FIGURE 3: Expression of endosialin and PDGFR- $\beta$ across sarcoma histotypes. Gene expression and semiquantitative IHC data for endosialin and PDGFR- $\beta$ in different histotypes of sarcoma. The distribution of the expression level in each subtype is represented by box plots, with the middle horizontal line representing the median and box representing 25th to 75th percentiles. (a) Endosialin IHC; (b) endosialin gene expression; (c) PDGFR- $\beta$ IHC; (d) PDGFR- $\beta$ gene expression; (e) and (f) endosialin and PDGFR- $\beta$ gene expression in bone sarcoma subtypes. $P$ values represent multigroup ANOVA $P$ values. 
TABle 3: Pairwise ANOVA $P$ values for endosialin and PDGFR- $\beta$ expression.

(a)

\begin{tabular}{|c|c|c|c|c|}
\hline & Undifferentiated & Leiomyosarcoma & Other & Liposarcoma \\
\hline & \multicolumn{4}{|c|}{ TEM-1 IHC } \\
\hline Undifferentiated & NA & $3.74 E-01$ & $2.12 E-01$ & $2.49 E-02$ \\
\hline Leiomyosarcoma & NA & NA & $5.79 E-01$ & $4.89 E-03$ \\
\hline Other & NA & NA & NA & $6.55 E-03$ \\
\hline \multirow[t]{2}{*}{ Liposarcoma } & NA & NA & NA & NA \\
\hline & \multicolumn{4}{|c|}{ TEM1 $\log _{2}$ expression } \\
\hline Undifferentiated & NA & $9.80 E-04$ & $8.00 E-02$ & $3.65 E-02$ \\
\hline Leiomyosarcoma & NA & NA & $4.30 E-01$ & $3.51 E-06$ \\
\hline Other & NA & NA & NA & $9.41 E-04$ \\
\hline Liposarcoma & NA & NA & NA & NA \\
\hline
\end{tabular}

(b)

\begin{tabular}{|c|c|c|c|c|}
\hline & Undifferentiated & Leiomyosarcoma & Other & Liposarcome \\
\hline & \multicolumn{4}{|c|}{ PDGFR- $\beta$ IHC } \\
\hline Undifferentiated & NA & $9.08 E-02$ & $7.12 E-03$ & $2.91 E-01$ \\
\hline Leiomyosarcoma & NA & NA & $1.01 E-01$ & $7.16 E-01$ \\
\hline Other & NA & NA & NA & $1.21 E-01$ \\
\hline \multirow[t]{2}{*}{ Liposarcoma } & NA & NA & NA & NA \\
\hline & \multicolumn{4}{|c|}{ PDGFR- $\beta \log _{2}$ expression } \\
\hline Undifferentiated & NA & $2.11 E-02$ & $4.22 E-02$ & $7.84 E-01$ \\
\hline Leiomyosarcoma & NA & NA & $5.01 E-01$ & $2.13 E-02$ \\
\hline Other & NA & NA & NA & $4.90 E-02$ \\
\hline Liposarcoma & NA & NA & $\mathrm{NA}$ & NA \\
\hline
\end{tabular}

(c)

\begin{tabular}{lccr}
\hline & Osteosarcoma & Ewing & Chondrosarcoma \\
\hline & & TEM1 log expression & $6.37 E-03$ \\
Osteosarcoma & NA & $9.43 E-01$ & $1.17 E-02$ \\
Ewing & NA & NA & NA \\
Chondrosarcoma & NA & NA & $7.00 E-02$ \\
\hline & & PDGFR- $\beta \log _{2}$ expression & $8.01 E-02$ \\
Osteosarcoma & NA & $1.65 E-02$ & NA \\
Ewing & NA & NA & NA \\
Chondrosarcoma & NA & & NA
\end{tabular}

and merck-NM_002609_at, respectively, and were $\log _{2}$ transformed. For other genes assessed in this work (FN1, COL1A1, COL1A2, COL4A1, COL4A2, COL4A3, COL4A4, COL4A5, COL4A6, CA9, EPAS1, and HSPG2), the corresponding probes are provided in Table 1. If a gene had multiple probes on the array, the $\log _{2}$ expression levels were averaged.

2.6. Statistical Methods. The $\log _{2}$ gene expression levels and IHC discrete values $(0,1,2$, and 3$)$ were used to compute the correlation (Pearson) coefficients between the mRNA and protein levels across sarcoma patients. Spearman correlation yielded very similar results. The $\mathrm{R}$ stats package (http://cran.r-project.org/web/packages/) was used to test expression and IHC levels versus sarcoma histotypes. More specifically, we used linear model and ANOVA analysis from the $\mathrm{R}$ packages. The survival package from $\mathrm{R}$ was used to generate Kaplan-Meier curves and perform log-rank test and the Cox proportional hazards modeling.

\section{Results}

We initially evaluated the expression of endosialin and PDGFR- $\beta$ in both primary tumor samples and metastatic lesions across a variety of tumor types in a total of 15,820 samples from the TCC cohort (Figure 1). As can be seen from these data, the level of expression of these two genes varies across tumor types but both genes are ubiquitously expressed (Figures 1(a) and 1(c)). These data also demonstrate that expression of both genes is retained in metastatic lesions (Figures 1(b) and 1(d)) at levels comparable to the primary tumor. There are consistently high levels of expression of both endosialin and PDGFR- $\beta$ in soft tissue tumors, which were 


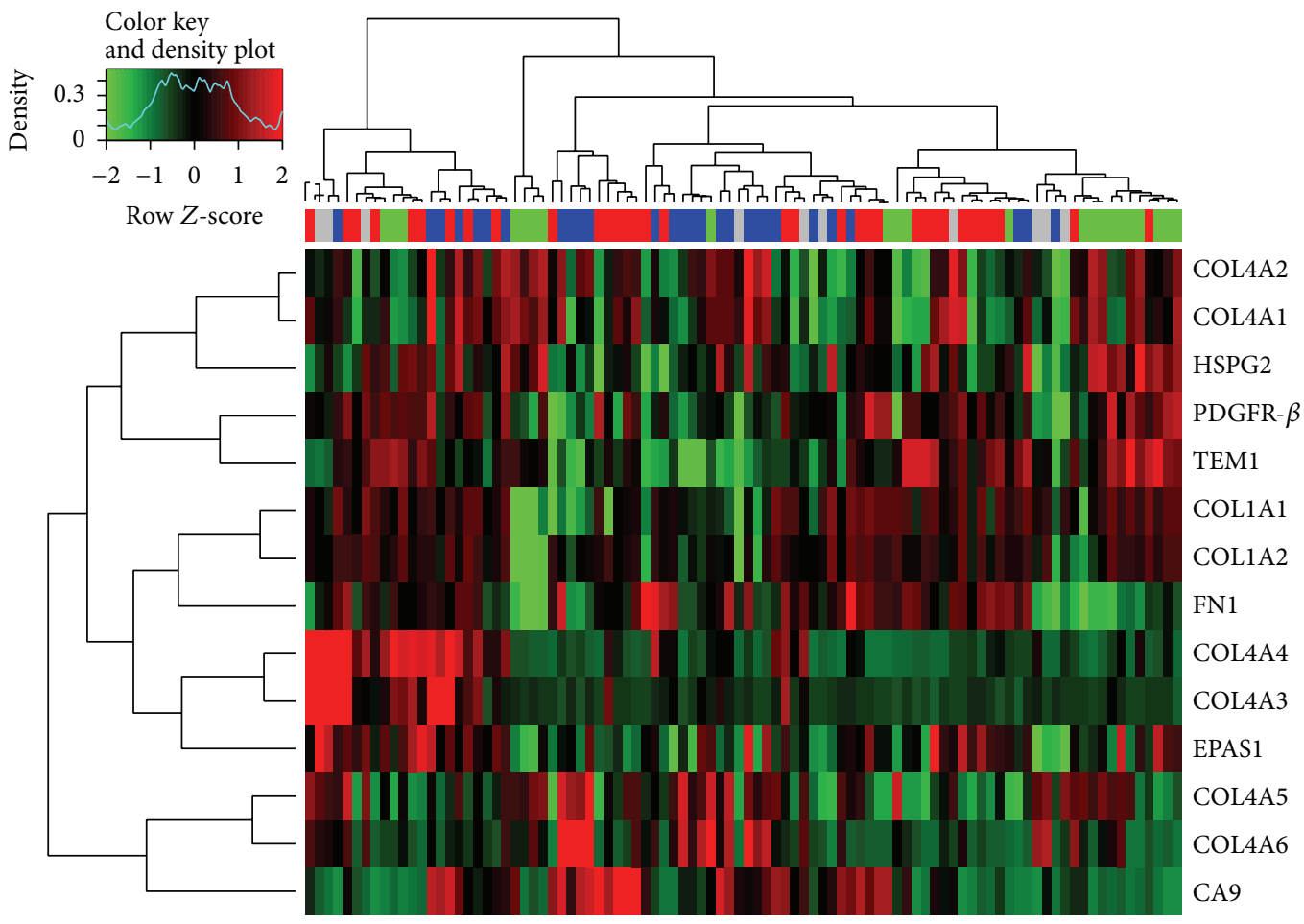

FIgURE 4: Heat map of expression of potential endosialin interacting proteins.

mostly sarcomas, relative to the other tumor types assessed. Across the entire data set there was a high correlation between the expression of endosialin and PDGFR- $\beta$ (Figure 2(a)).

To more thoroughly evaluate sarcomas, samples from 94 patients for which all data was available were identified (Table 2) and used in the present study. The mean age of the patients was 59 with a range of 19-90 years. Samples were categorized by histology in accordance with, but distinct from, the active randomized, blinded clinical trial (NCT01574716) with gemcitabine and docetaxel with or without MORAb-004 into 4 subgroups: leiomyosarcoma (28 subjects), liposarcoma (22 subjects), undifferentiated (34 subjects), and other (10 subjects: 4 with angiosarcoma and 6 with synovial sarcoma). The majority of subjects in this study presented with high grade tumors and were classified as stage III at diagnosis. The majority of samples $(55 ; 59 \%)$ were primary tumor resections, with the remainder representing relapsed or progressive metastatic samples $(39 ; 41 \%)$. As shown in Figure 2(b), the expression of endosialin and PDGFR- $\beta$ is highly correlated across these 94 sarcoma samples.

A good correlation was observed across the entire sarcoma sample set for endosialin and PDGFR- $\beta$ expression determined by both IHC and gene expression analysis (Figures $3(\mathrm{a})-3(\mathrm{~d}))$. The relative expression across all 4 sarcoma subgroups for both endosialin and PDGFR- $\beta$, both by IHC and gene expression analysis, shows that liposarcoma had slightly higher IHC scores and gene expression levels than the other subgroups analyzed (see Table 3 for pairwise comparisons). Bone sarcomas demonstrated consistently high endosialin and PDGFR- $\beta$ expression with chondrosarcoma having lower expression (Figures 3(e)-3(f)).
Since a number of potential interacting proteins and pathways have been described in the literature to be involved in endosialin biology, we further examined the expression of a number of extracellular matrix and hypoxia related genes. Figure 4 shows the heat map derived from these analyses with no obvious clustering of samples or histotypes. However, a number of positive correlations $(P<0.02)$ were identified between endosialin or PDGFR- $\beta$ IHC expression (Table 4) versus gene expression of this gene set, and by PDGFR- $\beta$ gene expression versus gene expression of the gene set (Table 5). Endosialin was most highly positively correlated to PDGFR- $\beta$ and HSPG2 (heparin sulphate proteoglycan 2) and negatively correlated to CAIX (carbonic anhydrase IX). PDGFR- $\beta$ was most highly positively correlated to FN1 (fibronectin) and negatively correlated to COL4A5 (collagen, type IV, alpha 5).

Finally, the relationship between endosialin gene expression and survival was evaluated relative to sarcoma histotype (Figure 5). While not significant $(P=0.09)$ there was a trend towards a survival benefit for higher endosialin gene expression in the liposarcoma subtype. It should be noted that these analyses were performed by bifurcation of the histotypes at the median of endosialin expression. In contrast, endosialin protein expression, determined by semiquantitative IHC using the $H$-score, was significantly $(P=0.026)$ associated with survival using an $H$-score cut point at the 75 th percentile $(H$-score $=100)$; that is, increased endosialin expression resulted in better survival for the entire cohort (Figure 6). Further, by Cox proportional hazards analysis which does not depend on any threshold, the $\log$ (hazards ratio) was $-0.0039 \pm 0.0016(P=0.015)$. 
TABLE 4: Endosialin and PDGFR- $\beta$ gene/protein expression correlations.

(a) Endosialin IHC correlation with gene expression

\begin{tabular}{lcc}
\hline Gene & Correlation & $P$ value \\
\hline PDGFR- $\beta$ & 0.27 & $9.63 E-03$ \\
TEM1 & 0.61 & $8.27 E-11$ \\
FN1 & -0.09 & $3.82 E-01$ \\
COL1A1 & 0.14 & $1.85 E-01$ \\
COL1A2 & 0.06 & $5.95 E-01$ \\
COL4A1 & 0.00 & $9.73 E-01$ \\
COL4A2 & -0.02 & $8.83 E-01$ \\
COL4A3 & -0.14 & $1.68 E-01$ \\
COL4A4 & -0.08 & $4.41 E-01$ \\
COL4A5 & -0.12 & $2.60 E-01$ \\
COL4A6 & -0.22 & $3.18 E-02$ \\
CAIX & -0.29 & $4.65 E-03$ \\
EPAS1 & 0.08 & $4.22 E-01$ \\
HSPG2 & 0.30 & $3.19 E-03$ \\
\hline
\end{tabular}

(b) PDGFR- $\beta$ IHC correlation with gene expression

\begin{tabular}{lcc}
\hline Gene & Correlation & $P$ value \\
\hline PDGFR- $\beta$ & 0.43 & $1.76 E-05$ \\
TEM1 & 0.26 & $1.25 E-02$ \\
FN1 & 0.44 & $1.07 E-05$ \\
COL1A1 & 0.32 & $1.75 E-03$ \\
COL1A2 & 0.32 & $1.59 E-03$ \\
COL4A1 & -0.16 & $1.31 E-01$ \\
COL4A2 & -0.19 & $7.32 E-02$ \\
COL4A3 & -0.06 & $5.38 E-01$ \\
COL4A4 & 0.08 & $4.33 E-01$ \\
COL4A5 & -0.42 & $2.43 E-05$ \\
COL4A6 & -0.30 & $3.35 E-03$ \\
CAIX & -0.22 & $3.45 E-02$ \\
EPAS1 & 0.21 & $3.91 E-02$ \\
HSPG2 & -0.05 & $6.37 E-01$ \\
\hline
\end{tabular}

PDGFR- $\beta H$-score, on the other hand, was not significant by the Cox model $(P=0.44)$.

\section{Discussion}

To our knowledge, this 15,820-sample cohort across 27 different cancer location types represents the largest reported for endosialin and PDGFR- $\beta$ expression. Soft tissue tumors, primarily composed of sarcomas, are at the high end of expression of endosialin which might support evaluation of this tumor type in a clinical setting. Additionally, expression of both endosialin and PDGFR- $\beta$ was maintained in metastatic lesions providing a potential target for advanced disease. This expression may be a reflection of the integral roles endosialin and PDGFR- $\beta$ have in tumor biology. In metastatic lesions, both endosialin and PDGFR- $\beta$ were expressed more highly in soft tissue tumors than in any of the other tumor types assessed. It is also important to note that there was a very high correlation between the expression of these two genes across the entire 15,820-sample set, as well as the 94 -sarcoma cohort.

It is now generally recognized that endosialin expression is present in tumor vasculature, specifically pericytes, as well as in activated macrophages within the tumor stroma [36]. The expression of endosialin in sarcomas is well documented in cell lines, including stem cell enriched side populations [37], and expression was maintained when cell lines were implanted in vivo and metastasized [24]. Further, endosialin expression, determined by IHC, in archived sarcoma samples has been reported [23]. In the present study, we demonstrated excellent concordance of endosialin expression by IHC and by gene expression analysis in a sarcoma cohort and both agree with and extend previous studies.

Agents targeting endosialin are now in the clinic with safety data reported from a phase I trial of the anti-endosialin therapeutic monoclonal antibody ontuxizumab (MORAb004) in advanced solid tumors [22]. Overall the agent was well tolerated with fatigue $(47.2 \%)$, headache (36.1\%), pyrexia (22.2\%), chills (19.4\%), and nausea (dose limiting toxicity, $13.9 \%)$ being reported and with infusion related reactions manageable with premedications. This agent is also being investigated in a recently enrolled phase II sarcoma trial.

Having access to the expression data for this sarcoma cohort allowed us to investigate potential gene associations beyond PDGFR- $\beta$ for a number of literature-reported endosialin binding partners and associated pathways. For example, studies demonstrated that fibronectin and collagens types I and IV are binding partners of endosialin [38]. Evidence for the criticality of endosialin expression in tumor growth and progression comes from the findings in glioblastoma cells and placental fibroblasts that endosialin expression is upregulated by hypoxia inducible factor-2 (HIF2) [39], produced as a result of rapid proliferation of tumor cells generating areas of hypoxia leading to the expression of HIF-1 and HIF-2, upregulated gene expression, and vascular remodeling. Animal models have further demonstrated that cancer invasion is stimulated by stromal microenvironments similar to those present in wound healing [40]. This observation suggests that growth factors implicated in wound healing such as transforming growth factor- $\beta$ (TGF- $\beta$ ) and PDGFR- $\beta$ may also play a role in altering the stromal host compartment in support of cancer.

Of the genes examined, the most significant correlations with endosialin expression were seen with PDGFR$\beta$, as expected, and HSPG2 and a negative correlation with CAIX. A significant but weaker negative correlation was also observed for COL4A6. Interestingly perhaps is that no correlation was seen between endosialin expression and HIF-2 expression. As noted above, HIF-2 expression has been reported to upregulate endosialin expression and also regulates CAIX expression. Further studies are clearly needed to elucidate the regulation of expression of endosialin. The expression of PDGFR- $\beta$ was highly correlated to fibronectin and highly negatively correlated to COL4A5. It is worth noting that endosialin expression was also negatively correlated to COL4A5 but did not reach significance. Similar to the results with endosialin, PDGFR- $\beta$ was significantly negatively correlated to COL4A6 as well as COL1A1 and COL1A2. 


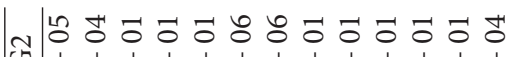

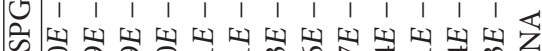

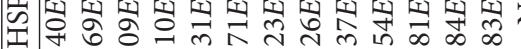
4

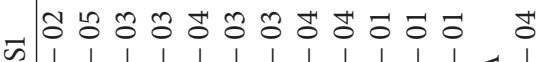

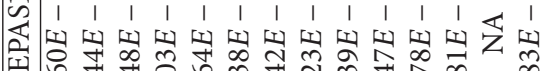

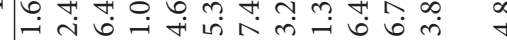

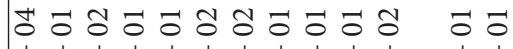

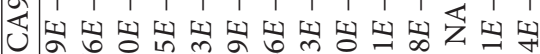
等

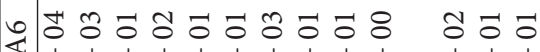

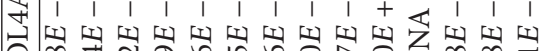

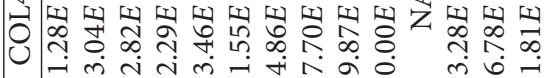

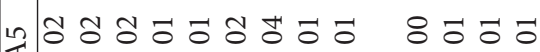
$\begin{array}{lllllllllllllll}4 & 1 & 1 & 1 & 1 & 1 & 1 & 1 & 1 & 1 & 4 & + & 1 & 1 & 1\end{array}$

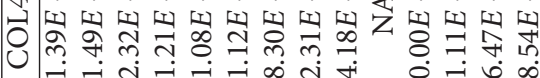

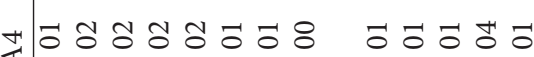

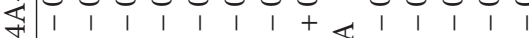

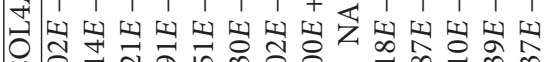
U

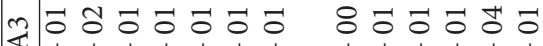

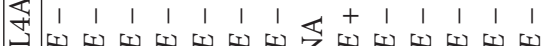

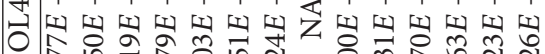
ن

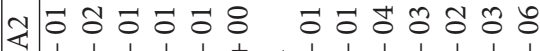
U

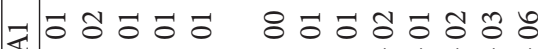

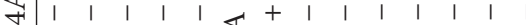

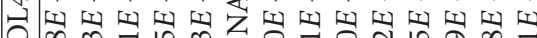
U

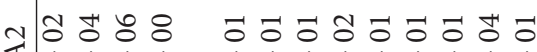

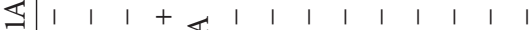

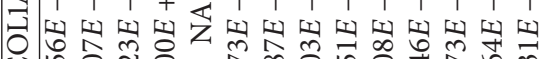

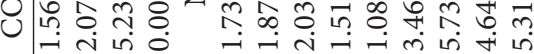

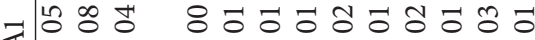

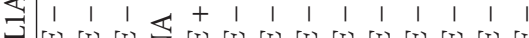

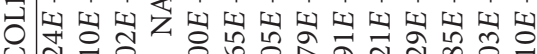

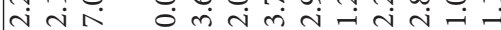
ठี

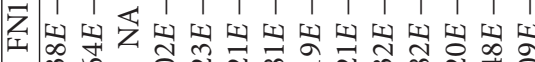

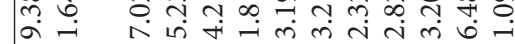

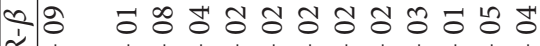

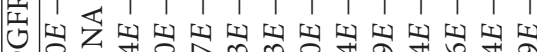

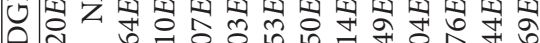
a I

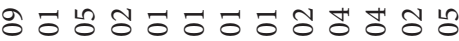

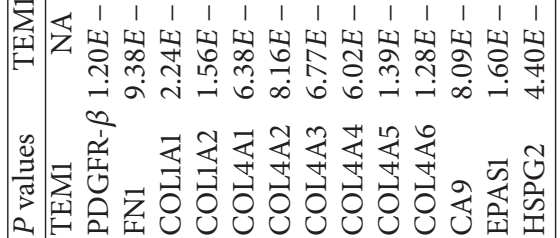

ป̂.

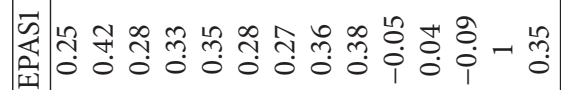

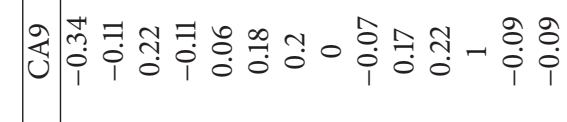

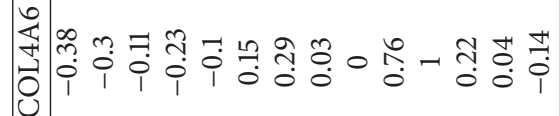

至

㚣

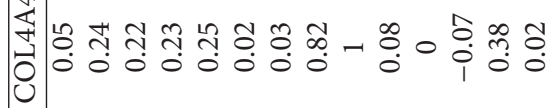

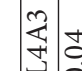

8

弯

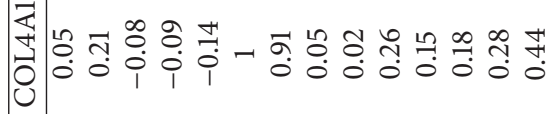

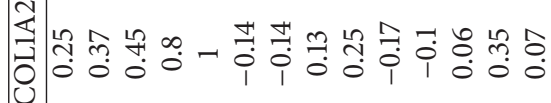

类

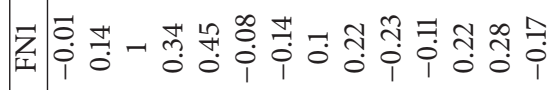

$\infty$

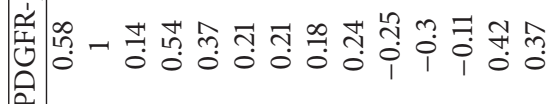

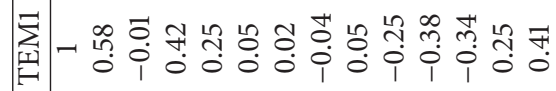

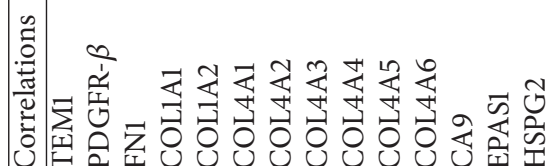




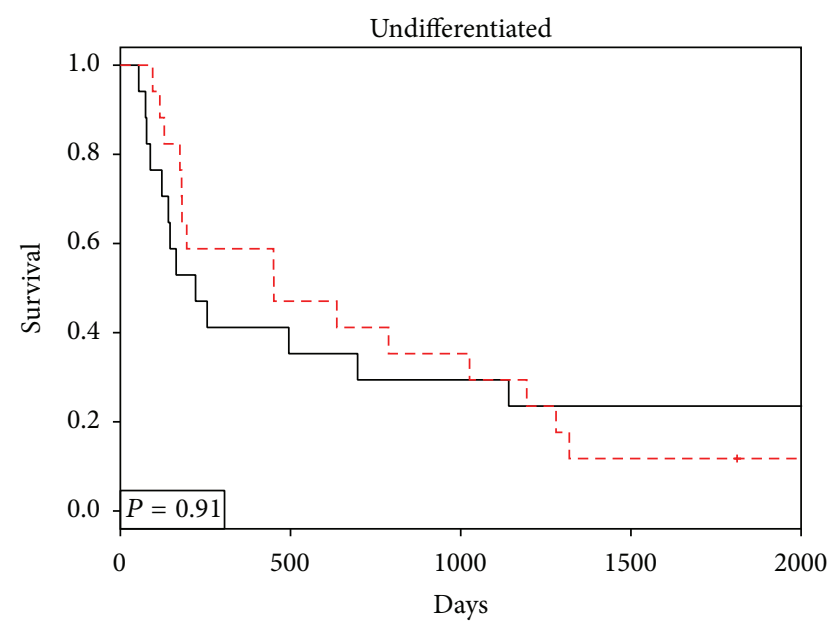

Expression $<$ median

- - Expression $>$ median

(a)

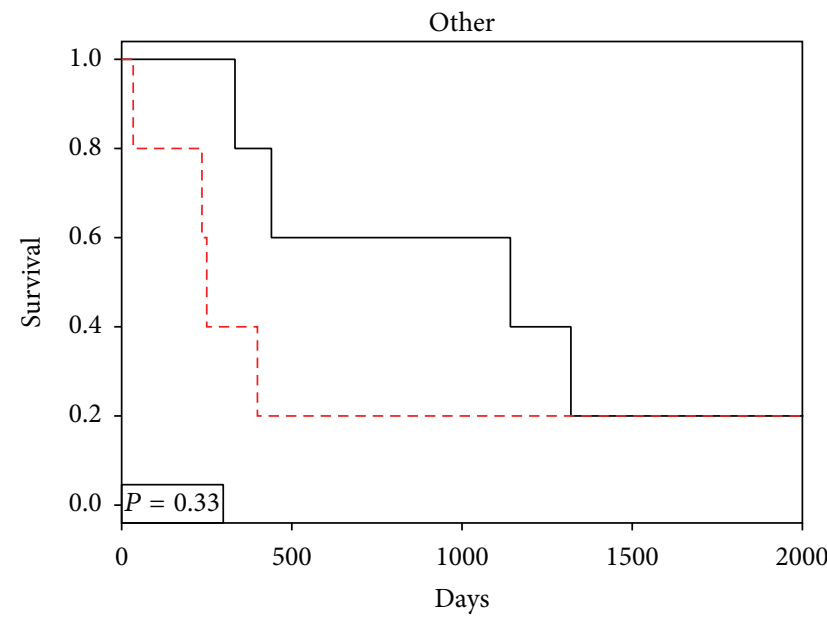

- Expression $<$ median

- - - Expression $>$ median

(c)

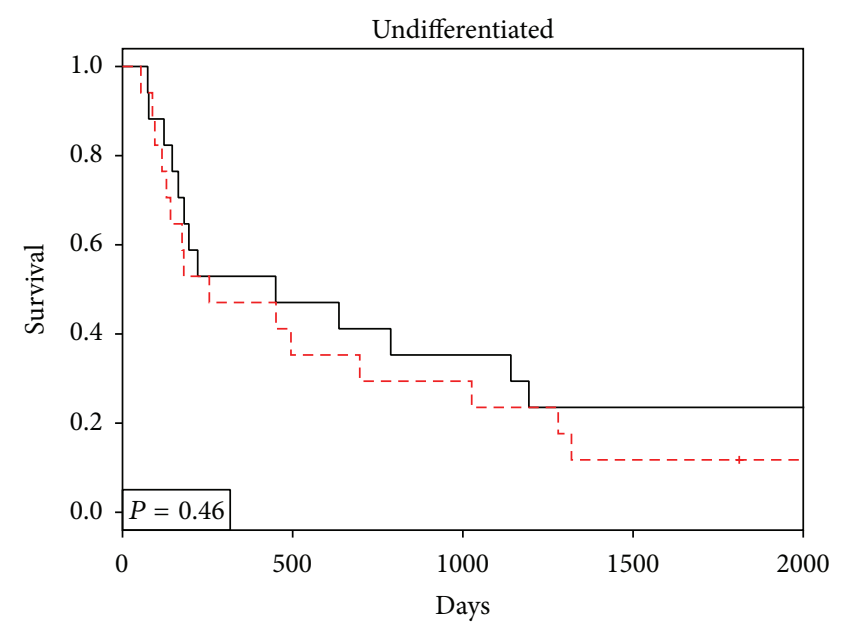

Expression $<$ median

- - - Expression $>$ median

(e)

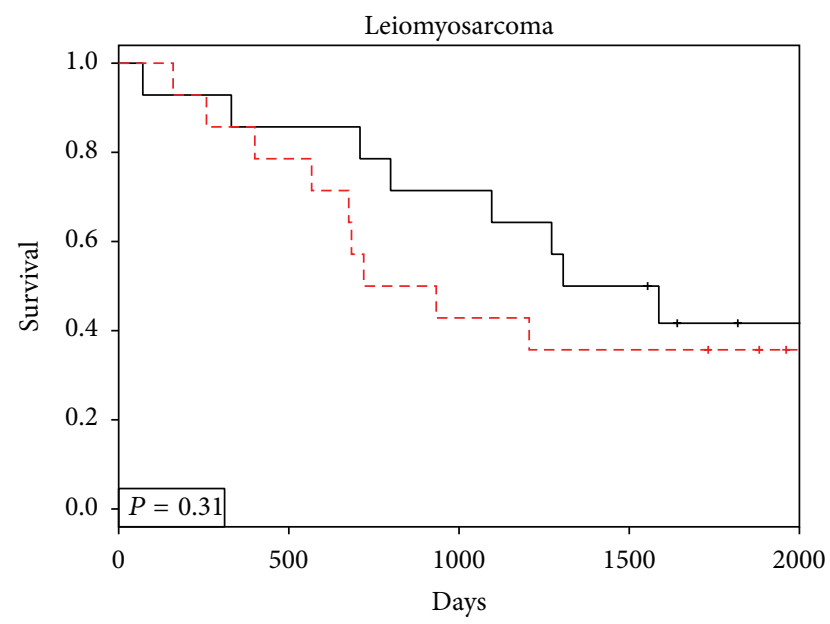

Expression $<$ median

- - Expression $>$ median

(b)

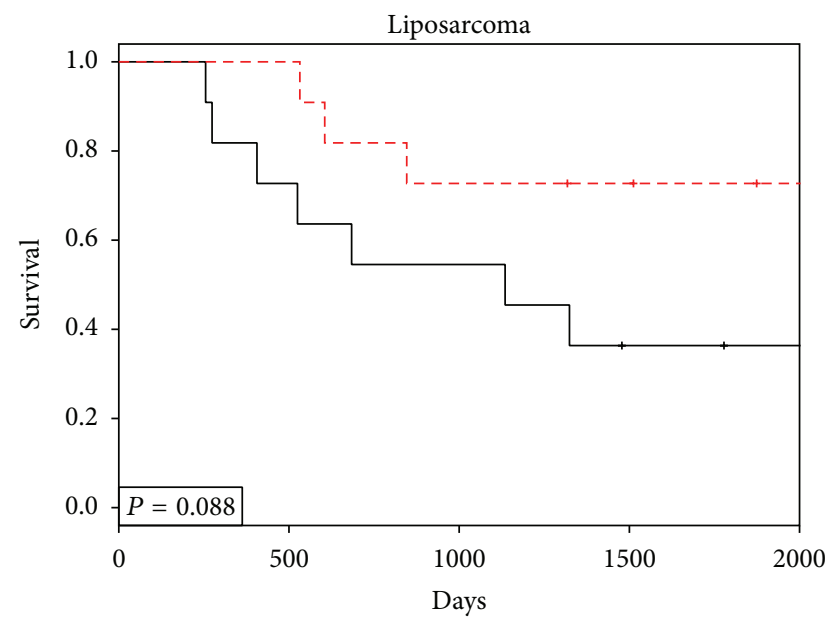

- Expression $<$ median

- - - Expression $>$ median

(d)

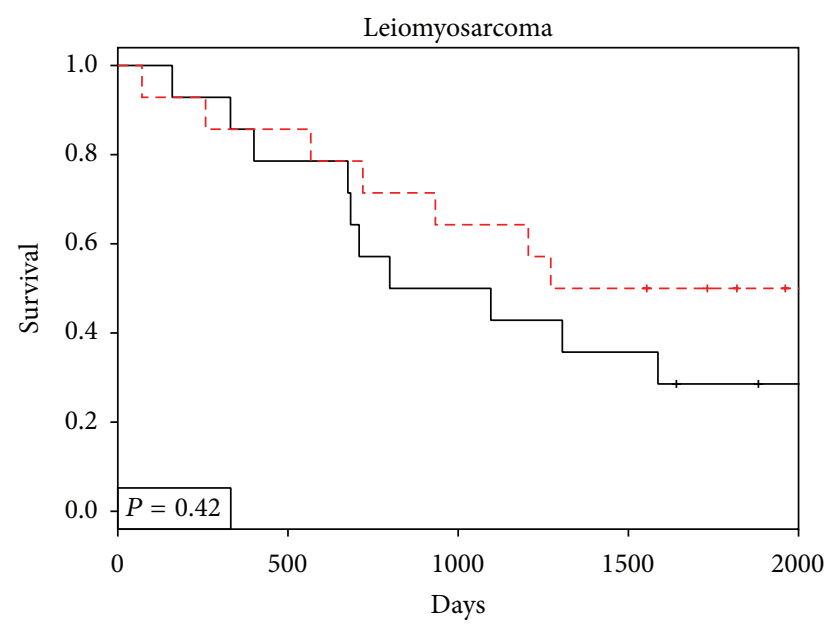

Expression $<$ median

- - - Expression $>$ median

(f)

Figure 5: Continued. 


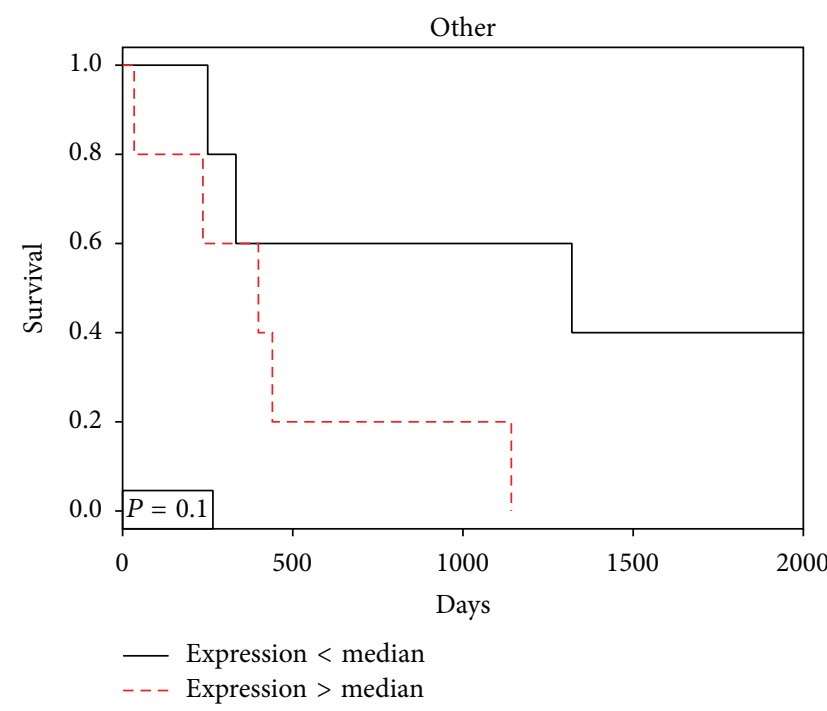

(g)

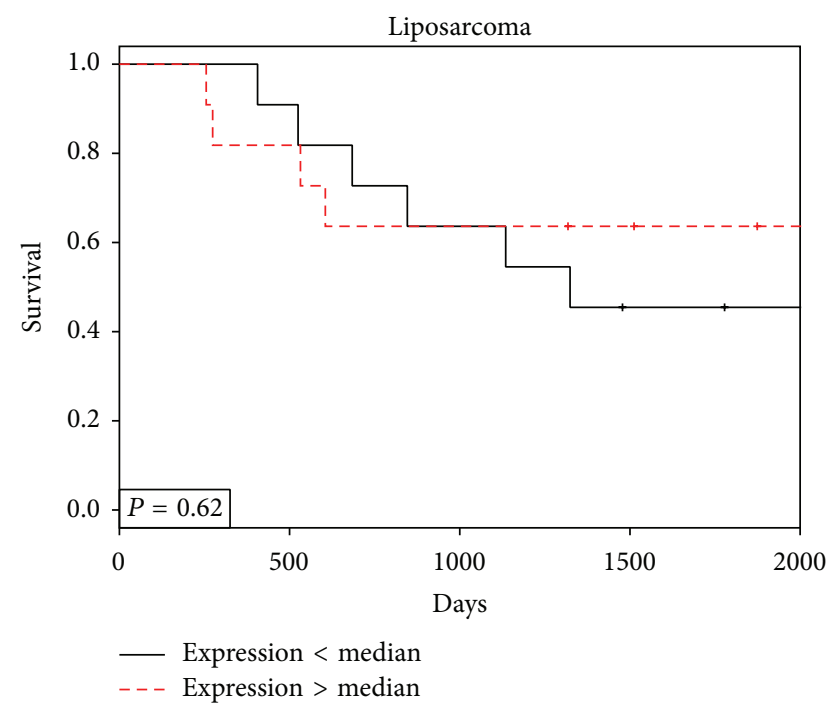

(h)

FIGURE 5: Endosialin and PDGFR- $\beta$ gene expression and outcomes in sarcoma histotypes. Endosialin ((a)-(d)) and PDGFR- $\beta$ ((e)(h)) expression versus overall survival in different histological subtypes of sarcoma. (a) and (e) Undifferentiated $(N=34)$; (b) and (f) leiomyosarcoma $(N=28)$; (c) and (g) other (angiosarcoma and synovial sarcoma) $(N=10)$; and (d) and (h) liposarcoma $(N=22)$.

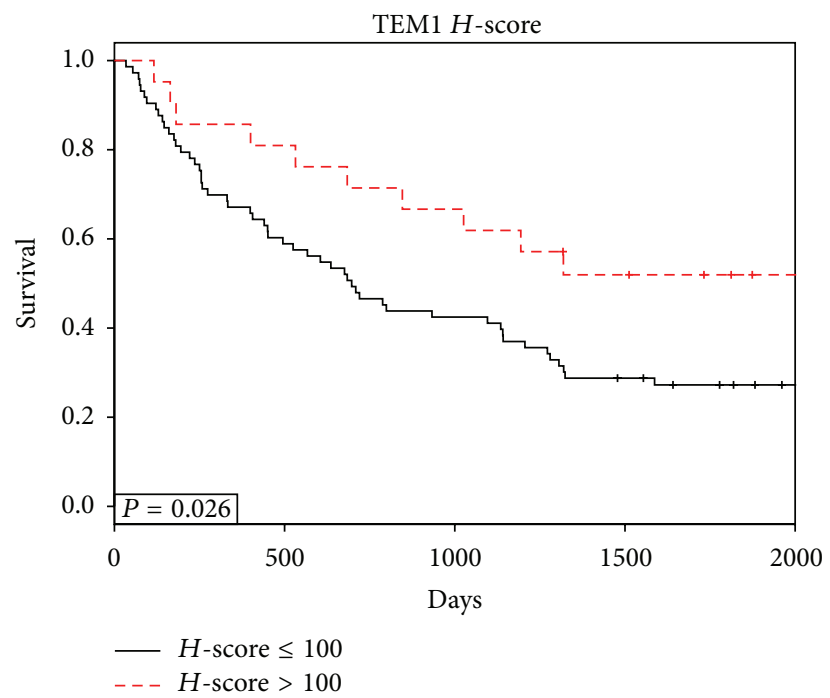

FIGURE 6: Endosialin protein expression (IHC) and outcomes in sarcoma. IHC was performed as described and slides scored by a Boardcertified pathologist. The figure represents endosialin $H$-score versus overall survival in the 94 sarcoma patients cohort. High $H$-score correlates to improved outcome.

While inconclusive, these data combined are suggestive of an interaction, either direct or indirect, between endosialin and PDGFR- $\beta$ and with extracellular matrix components (ECM) such as fibronectin and collagens. Indeed, in a recent study [41] on archival colorectal cancer specimens using fluorescent immunohistochemistry approaches, the architectural expression (tumor, stroma, and vessel) of endosialin, ECM components (fibronectin, collagens types I and IV), PDGFR- $\beta$, HIF-2, and CAIX demonstrated a complex interplay between endosialin and the tumor microenvironment. Importantly, this prior work also demonstrated that the architectural expression and quantitation of these endosialin-associated proteins was prognostic in colorectal cancer.

In the present sarcoma cohort, based on gene expression data, we were unable to demonstrate a clear correlation with endosialin-associated expression and overall survival. However, unlike the study on colorectal cancer, and absent laser microdissection, gene expression studies are burdened by averages with no architectural or contextual information. In the liposarcoma subcohort, which showed higher endosialin gene expression relative to the other subcohorts evaluated, there was a distinct trend, though not significant, 
towards increased survival with increased endosialin expression. Interestingly however, when endosialin expression by IHC was assessed across the entire 94-patient cohort, it was significantly predictive of survival, that is, prognostic, again with higher expression correlating with improved survival.

\section{Conclusions}

Taken together, the present results support a relationship between endosialin and PDGFR- $\beta$ in concert with the ECM. The exact nature of these relationships and their influence on the tumor microenvironment and ultimately tumor growth and metastasis are yet to be elucidated. However, the present data on a relatively large sarcoma cohort supports the evaluation of anti-endosialin therapies, such as ontuxizumab (MORAb-004), in the clinical setting of sarcoma.

\section{Conflict of Interests}

The authors declare that there is no conflict of interests regarding the publication of this paper.

\section{Authors' Contribution}

Daniel J. O'Shannessy and Damon R. Reed contributed equally to this work. Study conception and design were by Damon R. Reed and Daniel J. O'Shannessy; study supervision was by Damon R. Reed, Daniel J. O'Shannessy, Melissa Mitchell, and Shane Huntsman; data was acquired by David Fenstermacher, Hongyue Dai, Shane Huntsman, and Stephen Brantley; data analysis and interpretation were by Damon R. Reed, Daniel J. O'Shannessy, David Fenstermacher, Shane Huntsman, and Hongyue Dai; paper was prepared, reviewed, and approved by Damon R. Reed, Daniel J. O'Shannessy, Melissa Mitchell, Hongyue Dai, Stephen Brantley, Shane Huntsman, and David Fenstermacher.

\section{References}

[1] W. J. Rettig, P. Garin-Chesa, J. H. Healey, S. L. Su, E. A. Jaffe, and L. J. Old, "Identification of endosialin, a cell surface glycoprotein of vascular endothelial cells in human cancer," Proceedings of the National Academy of Sciences of the United States of America, vol. 89, no. 22, pp. 10832-10836, 1992.

[2] S. Christian, H. Ahorn, A. Koehler et al., "Molecular cloning and characterization of endosialin, a C-type lectin-like cell surface receptor of tumor endothelium," The Journal of Biological Chemistry, vol. 276, no. 10, pp. 7408-7414, 2001.

[3] J. Feng, A. Mantesso, C. De Bari, A. Nishiyama, and P. T. Sharp, "Dual origin of mesenchymal stem cells contributing to organ growth and repair," Proceedings of the National Academy of Sciences of the United States of America, vol. 108, no. 16, pp. 65036508, 2011.

[4] G. Bergers and S. Song, "The role of pericytes in blood-vessel formation and maintenance," Neuro-Oncology, vol. 7, no. 4, pp. 452-464, 2005.

[5] A. F. Olumi, G. D. Grossfeld, S. W. Hayward, P. R. Carroll, T. D. Tlsty, and G. R. Cunha, "Carcinoma-associated fibroblasts direct tumor progression of initiated human prostatic epithelium," Cancer Research, vol. 59, no. 19, pp. 5002-5011, 1999.
[6] V. Nehls and D. Drenckhahn, "The versatility of microvascular pericytes: from mesenchyme to smooth muscle?" Histochemistry, vol. 99, no. 1, pp. 1-12, 1993.

[7] G. Lin, M. Garcia, H. Ning et al., "Defining stem and progenitor cells within adipose tissue," Stem Cells and Development, vol. 17, no. 6, pp. 1053-1063, 2008.

[8] M. Crisan, S. Yap, L. Casteilla et al., "A perivascular origin for mesenchymal stem cells in multiple human organs," Cell Stem Cell, vol. 3, no. 3, pp. 301-313, 2008.

[9] B. Alliot-Licht, D. Hurtrel, and M. Gregoire, "Characterization of $\alpha$-smooth muscle actin positive cells in mineralized human dental pulp cultures," Archives of Oral Biology, vol. 46, no. 3, pp. 221-228, 2001.

[10] S. Shi and S. Gronthos, "Perivascular niche of postnatal mesenchymal stem cells in human bone marrow and dental pulp," Journal of Bone and Mineral Research, vol. 18, no. 4, pp. 696-704, 2003.

[11] B. Elenbaas and R. A. Weinberg, "Heterotypic signaling between epithelial tumor cells and fibroblasts in carcinoma formation," Experimental Cell Research, vol. 264, no. 1, pp. 169$184,2001$.

[12] R. Montesano, G. Schaller, and L. Orci, "Induction of epithelial tubular morphogenesis in vitro by fibroblast-derived soluble factors," Cell, vol. 66, no. 4, pp. 697-711, 1991.

[13] D. L. Hardie, M. J. Baldwin, A. Naylor et al., "The stromal cell antigen CD248 (endosialin) is expressed on naive $\mathrm{CD} 8^{+}$human T cells and regulates proliferation," Immunology, vol. 133, no. 3, pp. 288-295, 2011.

[14] K. Forsberg, I. Valyi-Nagy, C.-H. Heldin, M. Herlyn, and B. Westermark, "Platelet-Derived Growth Factor (PDGF) in oncogenesis: development of a vascular connective tissue stroma in xenotransplanted human melanoma producing PDGF-BB," Proceedings of the National Academy of Sciences of the United States of America, vol. 90, no. 2, pp. 393-397, 1993.

[15] B. Tomkowicz, K. Rybinski, D. Sebeck et al., "Endosialin/TEM1/CD248 regulates pericyte proliferation through PDGF receptor signaling," Cancer Biology and Therapy, vol. 9, no. 11, pp. 908-915, 2010

[16] K. A. Rmali, M. C. A. Puntis, and W. G. Jiang, "Prognostic values of tumor endothelial markers in patients with colorectal cancer," World Journal of Gastroenterology, vol. 11, no. 9, pp. 1283-1286, 2005.

[17] L. F. Brown, A. J. Guidi, S. J. Schnitt et al., "Vascular stroma formation in carcinoma in situ, invasive carcinoma, and metastatic carcinoma of the breast," Clinical Cancer Research, vol. 5, no. 5, pp. 1041-1056, 1999.

[18] G. Davies, G. H. Cunnick, R. E. Mansel, M. D. Mason, and W. G. Jiang, "Levels of expression of endothelial markers specific to tumour-associated endothelial cells and their correlation with prognosis in patients with breast cancer," Clinical and Experimental Metastasis, vol. 21, no. 1, pp. 31-37, 2004.

[19] H. Dolznig, N. Schweifer, C. Puri et al., "Characterization of cancer stroma markers: in silico analysis of an mRNA expression database for fibroblast activation protein and endosialin," Cancer Immunity, vol. 5, article 10, 2005.

[20] J. Brady, J. Neal, N. Sadakar, and P. Gasque, "Human endosialin (tumor endothelial marker 1) is abundantly expressed in highly malignant and invasive brain tumors," Journal of Neuropathology and Experimental Neurology, vol. 63, no. 12, pp. 1274-1283, 2004.

[21] M. A. Huber, N. Kraut, N. Schweifer et al., "Expression of stromal cell markers in distinct compartments of human skin 
cancers," Journal of Cutaneous Pathology, vol. 33, no. 2, pp. 145$155,2006$.

[22] L. A. Diaz Jr., C. M. Coughlin, S. C. Weil et al., "A first-inhuman phase I study of MORAb-004, a monoclonal antibody to endosialin in patients with advanced solid tumors," Clinical Cancer Research, vol. 21, no. 6, pp. 1281-1288, 2015.

[23] C. Rouleau, M. Curiel, W. Weber et al., "Endosialin protein expression and therapeutic target potential in human solid tumors: sarcoma versus carcinoma," Clinical Cancer Research, vol. 14, no. 22, pp. 7223-7236, 2008.

[24] C. Rouleau, R. Smale, Y.-S. Fu et al., "Endosialin is expressed in high grade and advanced sarcomas: evidence from clinical specimens and preclinical modeling," International Journal of Oncology, vol. 39, no. 1, pp. 73-89, 2011.

[25] A. Weiss, J. Gill, J. Goldberg et al., "Advances in therapy for pediatric sarcomas," Current Oncology Reports, vol. 16, article 395, 2014.

[26] E. K. Amankwah, A. P. Conley, and D. R. Reed, "Epidemiology and therapies for metastatic sarcoma," Clinical Epidemiology, vol. 5, no. 1, pp. 147-162, 2013.

[27] M. Van Glabbeke, J. Verweij, I. Judson, and O. S. Nielsen, "Progression-free rate as the principal end-point for phase II trials in soft-tissue sarcomas," European Journal of Cancer, vol. 38, no. 4, pp. 543-549, 2002.

[28] D. A. Fenstermacher, R. M. Wenham, D. E. Rollison, and W. S. Dalton, "Implementing personalized medicine in a cancer center," Cancer Journal, vol. 17, no. 6, pp. 528-536, 2011.

[29] E. Kiyohara, N. Donovan, L. Takeshima et al., "Endosialin expression in metastatic melanoma tumor microenvironment vasculature: potential therapeutic implications," Cancer Microenvironment, vol. 8, no. 2, pp. 111-118, 2015.

[30] F. R. Hirsch, M. Varella-Garcia, P. A. Bunn Jr. et al., "Epidermal growth factor receptor in non-small-cell lung carcinomas: correlation between gene copy number and protein expression and impact on prognosis," Journal of Clinical Oncology, vol. 21, no. 20, pp. 3798-3807, 2003.

[31] H. Ishibashi, T. Suzuki, S. Suzuki et al., "Sex steroid hormone receptors in human thymoma," Journal of Clinical Endocrinology and Metabolism, vol. 88, no. 5, pp. 2309-2317, 2003.

[32] J. Cronin, E. McAdam, A. Danikas et al., "Epidermal Growth Factor Receptor (EGFR) is overexpressed in high-grade dysplasia and adenocarcinoma of the esophagus and may represent a biomarker of histological progression in Barrett's Esophagus (BE)," The American Journal of Gastroenterology, vol. 106, no. 1, pp. 46-56, 2011.

[33] D. A. Cohen, D. J. Dabbs, K. L. Cooper et al., "Interobserver agreement among pathologists for semiquantitative hormone receptor scoring in breast carcinoma," American Journal of Clinical Pathology, vol. 138, no. 6, pp. 796-802, 2012.

[34] R. Pirker, J. R. Pereira, J. von Pawel et al., "EGFR expression as a predictor of survival for first-line chemotherapy plus cetuximab in patients with advanced non-small-cell lung cancer: analysis of data from the phase 3 FLEX study," The Lancet Oncology, vol. 13, no. 1, pp. 33-42, 2012.

[35] E. A. Welsh, S. A. Eschrich, A. E. Berglund, and D. A. Fenstermacher, "Iterative rank-order normalization of gene expression microarray data," BMC Bioinformatics, vol. 14, article 153, 2013.

[36] J. G. Facciponte, S. Ugel, F. De Sanctis et al., "Tumor endothelial marker 1-specific DNA vaccination targets tumor vasculature," Journal of Clinical Investigation, vol. 124, no. 4, pp. 1497-1511, 2014.
[37] C. Rouleau, J. Sancho, J. Campos-Rivera, and B. A. Teicher, "Endosialin expression in side populations in human sarcoma cell lines," Oncology Letters, vol. 3, no. 2, pp. 325-329, 2012.

[38] B. Tomkowicz, K. Rybinski, B. Foley et al., "Interaction of endosialin/TEM1 with extracellular matrix proteins mediates cell adhesion and migration," Proceedings of the National Academy of Sciences of the United States of America, vol. 104, no. 46, pp. 17965-17970, 2007.

[39] A. Ohradanova, K. Gradin, M. Barathova et al., "Hypoxia upregulates expression of human endosialin gene via hypoxiainducible factor 2," British Journal of Cancer, vol. 99, no. 8, pp. 1348-1356, 2008.

[40] H. F. Dvorak, “Tumors: wounds that do not heal. Similarities between tumor stroma generation and wound healing," The New England Journal of Medicine, vol. 315, no. 26, pp. 1650-1659, 1986.

[41] D. J. O’Shannessy, E. B. Somers, L. K. Chandrasekaran, N. C. Nicolaides, J. Bordeaux, and M. D. Gustavson, "Influence of tumor microenvironment on prognosis in colorectal cancer: tissue architecture-dependent signature of endosialin (TEM-1) and associated proteins," Oncotarget, vol. 5 , no. 12 , pp. $3983-$ 3995, 2014. 


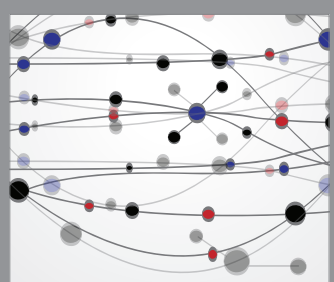

The Scientific World Journal
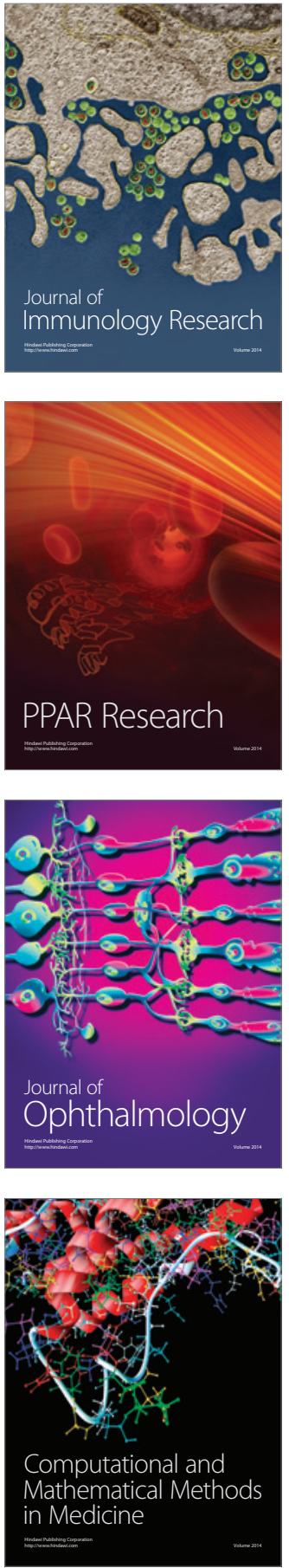

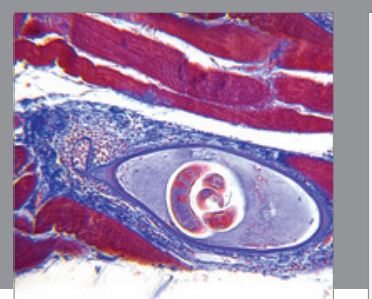

Gastroenterology Research and Practice

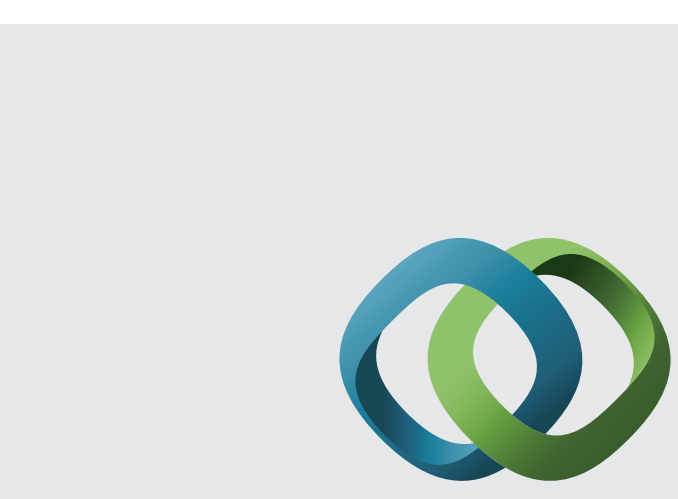

\section{Hindawi}

Submit your manuscripts at

http://www.hindawi.com
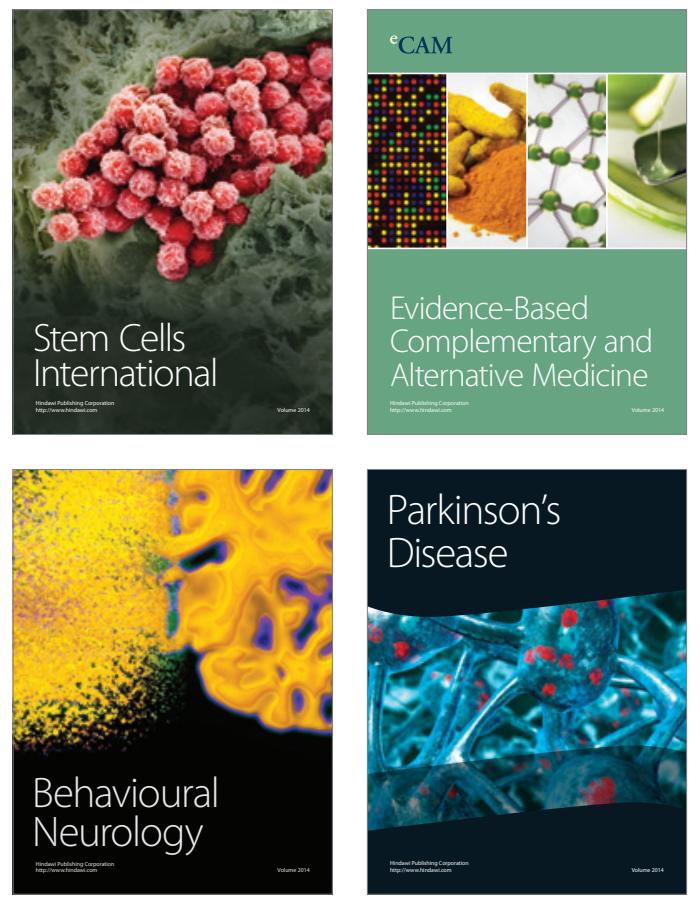
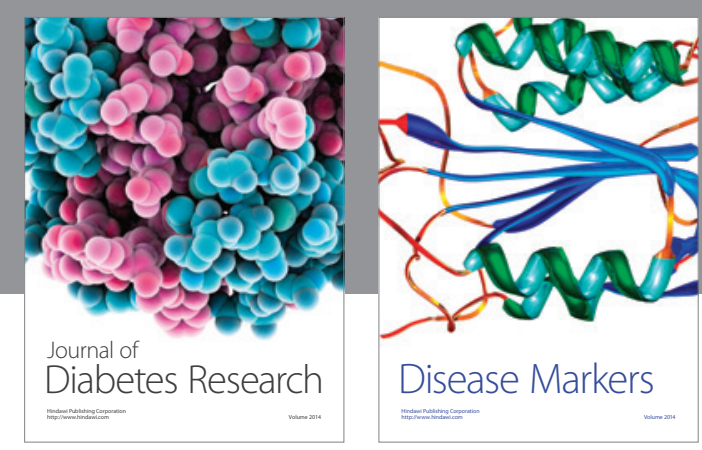

Disease Markers
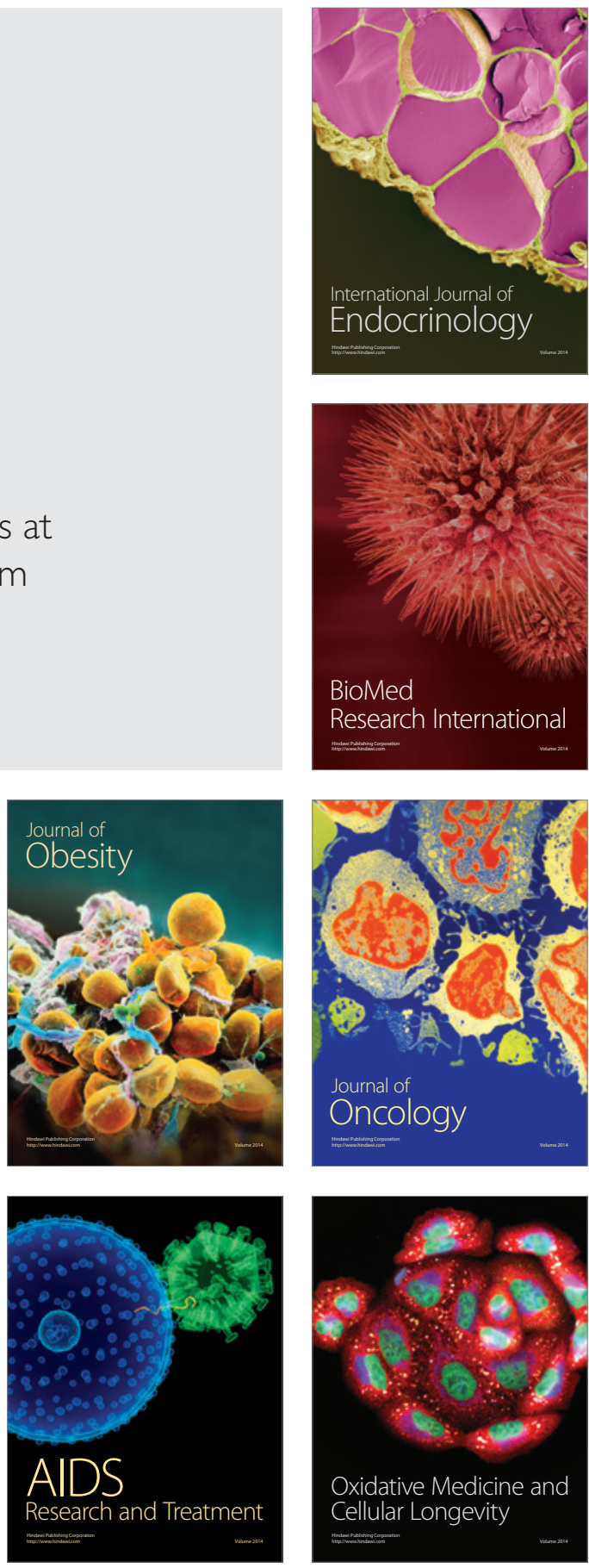